\title{
Editorial
}

\section{Towards More Personal and Integrated Understanding of the Sustainability Phenomenon}

Dear readers of the JTES and members of Daugavpils University UNESCO CHAIR NETWORK OF JTES \& DCSE. Since its foundation, JTES has developed its specific relationships with its readers and authors through an open network. The network has been established gradually, changing its name time from time. Changes in the network all these years have provided an opportunity to get involved in the generation and development of a specific theme of the JTES. The common interest in the phenomenon of sustainability and its relation to sustainable development and education has marked the trajectory of the JTES and the JTES network, which shows that even complex phenomena can be addressed and solved by those who cannot help but ask important questions about the world we live in, who we are and how we treat the world by acting and living in it.

Attitudes towards such deeply focused issues can vary. There are times when someone is satisfied with shallow answers and a quiet life that does not cause problems. However, this will not be the case found in the perception of life by people open to life. In recent years, we have increasingly understood our relationship with the environment in which we find the meaning of our lives and our shared call to understand and formulate a sense of living reality that goes beyond specific desires and pragmatic values. We are addressing complex and broad questions, we are concerned about alienation from the environment, and we are experiencing exposure to various counterfeits that have polluted the environment, both literally and especially in terms of humanity. If it bothers us, then it is a reason to study our own attitudes, to look into the attitudes of others, and it will be a challenge to face our understanding of the sustainability phenomenon.

Since 2007, when the journal was included in the Scopus database, the authors of JTES have created and affirmed that notions of sustainability are generated as deeply personal, through which we establish our dialogue on the essence of the world and humanity. Through our understanding, we also create scientific research.

In this volume of the journal, it is unnecessary to give recommendations for the development of articles, as the answer to the question about the specific requirements of the JTES is redundant. You need to read the articles of the present volume and, undoubtedly, you will find your issue or theme that may result in the prospective article of the JTES.

The interests of our authors are different, but this volume summarizes the attempts to move higher education towards more sustainable development. As usual, the authors offer us experiences and ideas from different countries. They come from Spain, the United Kingdom, Italy, Germany, Russia, Finland, Vietnam, Portugal and Latvia.

We would like to thank the authors who show us different options chosen for different paths and move towards the development of humane higher education.

We wish you a pleasant reading and fruitful discovery of your own idea for an article. Our readers will find them in future issues of the JTES. 
The paper "A Holistic Approach to Education for Sustainability: Ecofeminism as a Tool to Enhance Sustainability Attitudes in Pre-service Teachers” by Yolanda EchegoyenSanz and Antonio Martín-Ezpeleta from the University of Valencia, Spain, highlights the necessity of instructional changes in teacher training to achieve holistic education for sustainable development. One option is to use a transdisciplinary focus in teacher training. This is the method described in the paper by implementing an educational intervention with pre-service teachers around the ecofeminist movement approaching it from different perspectives (environmental, social, economic etc.). Through a process of didactic transposition, these prospective teachers have learned a new methodology to implement holistic education in their professional future. The impact of the intervention has also been verified with a validated questionnaire, the results of which show a statistically significant improvement in their sustainability attitudes.

The paper entitled "The IraunIK and IraunIR Questionnaires: Assessment of Transversal Competencies for Sustainability” by Itziar Rekalde-Rodríguez, Pilar GilMolina and Esther Cruz-Iglesias from the University of the Basque Country, Spain, show the process of validity and reliability of the questionnaires for the transferability. These questionnaires aim at finding out the perception of students and lecturers about the competencies and learning outcomes for sustainability that students develop through their participation in the international cross-border project of the Bordeaux-Euskampus "Ocean i3: Blue Skills for the Development of the Blue Economy in the Basque-Aquitaine Cross-Border Coast". Taking into account that one of the difficulties faced by teachers in ESD is the monitoring of the competencies to be developed by their students, this paper offers a proposal of learning outcomes that teachers can use to guide their system of work and later assessment. In addition, the items refer to sustainable development competencies but they are not linked to a specific area of knowledge, neither to a territorial university context; therefore, these items can be used in any learning process on sustainability in higher education.

Arinola Adefila with her co-authors from the United Kingdom, Italy and Germany in their paper "Ecologized Collaborative Online International Learning: Tackling Wicked Sustainability Problems Through Education for Sustainable Development" emphasizes that Education for Sustainable Development (ESD) is increasingly embedded in higher education due to the current emphasis on tackling the environmental crisis. Similarly, Civic Society Organizations are expanding their mobilization and practical action in communities. These approaches can reach almost all people on the planet and open avenues for effective global action around sustainable development. It is important to connect both learners and develop agents of change in society. In this paper, the authors focus on how digital resources can support democratization of knowledge production and improve equitable citizen participation in ESD and practical action at the local and global levels. The paper investigates structures, processes and components that support transnational collaboration in digital spaces, particularly, around the enhancement of sustainable environmental attitudes. The study uses the Collaborative Online International Learning (COIL) as a basis to develop EcoCOIL - a versatile model for expanding coalition building tools and principles - to promote environmental citizenship and develop multi-layered communities of practice. EcoCOIL focuses on co-created wisdom sharing across intercultural, intergenerational and transdisciplinary actors; it brings an innovative, participatory angle to curriculum development by integrating lifelong learning principles and practical facilitation of sustainable behavior within communities in real time. 
Jens Hepper from Germany in his paper "Making Change Visible - An Explorative Case Study of Dealing With Climate Change Deniers in Forest Education" addresses the issue of climate change denial among students in their first year of vocational education. It was possible to shake the belief that human-made climate change was not happening through letting students measure the potential of natural forest vegetation and compare their findings with those gathered by their peers nine years earlier. The comparison revealed that old forests had turned into ecosystems, which were adapted for dryer warmer climates. In terms of education for sustainable development, forest education and biology lessons offer the opportunity to establish a long-term project, in which peer-to-peer-learning over generations of students is possible, with a high rate of acceptance of the results generated by the former students.

Yevgeniya Gerasimova, Svetlana Dvoryatkina, Olga Savvina and Sergey Shcherbatykh from Bunin Yelets State University of the Russian Federation in their article "Implementing a Spiritual and Moral Education Program for Maths Teachers" solve the problem of commitment of modern pedagogical education to sustainable development. The authors propose new didactic solutions to form this phenomenon among math teachers in postgraduate education by establishing spirituality as a factor of educational system stability. The research results showed a significant increase in value-semantic, communicative, reflexive, motivational and critical parameters after implementing the spiritual and moral education program. The methods and content of mathematics were used to fundamentalize the teachers' personality with value-semantic guidelines and enrich them with spiritual and moral values, ensuring their professional development, and guiding them to overcome the crisis and transition to sustainable social development.

The paper "Student Teachers' Change Agency in Education for Sustainable Development" by Teija Koskela and Sirpa Kärkkäinen from Finland discusses how to promote education for sustainable development at university level. The main aim of the paper was to analyze Finnish student teachers' perceptions of change agency and sustainable development. The findings of this paper confirmed previous studies showing that student teachers' perceptions of sustainable development were quite narrow: Student teachers wrote mainly about social dimensions of sustainable development and few of them considered economic or environmental dimensions of sustainable development. The results provide new information about the current state of student teachers' perceptions of change agency in the teacher education context. Teacher education should focus more on a holistic view of sustainable development aspects. These findings might be useful in implementing teacher education curricula.

The research paper entitled "What Does Education for Sustainable Development Offer in Initial Teacher Training? A Systematic Review" by $\mathbf{M}^{\text {a }}$ del Carmen PegalajarPalomino, Antonio Burgos-García and Estefania Martinez-Valdivia contributes to the Journal of Teacher Education for Sustainability an international systematic review (in different databases of scientific and academic prestige such as Web of Science and Scopus in the period of 2010-2020) with the purpose of evidencing Education for Sustainable Development in higher education, specifically, collecting and analyzing practical and/ or curricular experiences in the training of teachers who will be key agents in the education of our students, guaranteeing an inclusive and equitable quality education, and promoting lifelong learning opportunities for all (goal 4 of the United Nations Agenda 2030).

The paper entitled "The Professional Development of Academic Staff in Higher Education Institution" by Duc Huu Pham from Vietnam declares that higher education 
is given increasing recognition by national governments and international agencies throughout the world to become a crucial incentive for sustainable development goals. In the national development of intellectual force at present, the Vietnam policy of education and training, which is of great importance, is the decisive factor for the economic growth and social development as set out by the government. Therefore, the educational development is the responsibility of both the government and the society. The author emphasizes that the academic staff of higher education institutions is the core force, playing a decisive role in ensuring the quality of higher education as in the case of the International University - Vietnam National University Ho Chi Minh City. This study may contribute to developing the quality of higher education institutions regarding the promotion of international publications by the higher education faculties.

Maria Eduarda Ferreira and Rui Pitarma from Portugal in their paper "Enhancing Ecocentric Environmental Attitudes: An Experience of Science Teaching to Inspire Students to Value Trees" state that the ecosphere has undergone significant and rapid changes, in which deforestation, the lack of care and protection of the tree are included. The paper analyzes an experience of science teaching to inspire university students to value trees. In the educational practice developed, the authors found that the exploration of the physiological characteristic - temperature -, with the use of the thermographic image, allowed (re)signifying the concept of "living being" - tree. The results indicate that the teaching methodology assuming the professor's mediating role provided the context for developing critical-reflexive, propitiative of the development of ecocentric environmental attitudes. Knowing whether an attitude on nature is right or wrong is to understand why it is wrong or right. Therefore, professors should be more aware of environmental issues and motivated to innovate their educational practices.

The paper entitled "More Personal Knowledge for More Sustainable Higher Education" by Ilga Salite, Ilona Fjodorova, Inese Butlere and Oksana Ivanova from Latvia aims at considering the characteristics of the Anthropocene era from a broader perspective and emhasizing the possibilities of pedagogy to reduce the current unsustainability of higher education. For the case study the authors have used the processes taking place at the phenomenon level, which are known as the first-person perspective characterized by an active and dynamic connection with the environment. The authors have recognized the need to use the first-person perspective and adaptive learning opportunities more carefully. In this way, pedagogy can gain new experiences for a more holistic understanding of individual experience and enhance the use of the unique abilities of adaptive learning to prototype more personal knowledge in order to build more sustainable higher education.

Ilga Salīte, Ilona Fjodorova and Oksana Ivanova 